\title{
Graphene-polyaniline composite film modified electrode for voltammetric determination of 4-aminophenol
}

\author{
Yang Fan ${ }^{\mathrm{a}, *}$, Jin-Hang Liu ${ }^{\mathrm{a}}$, Chun-Peng Yang ${ }^{\mathrm{b}}$, Meng $\mathrm{Yu}^{\mathrm{a}}$, Peng Liu ${ }^{\mathrm{a}}$ \\ a College of Chemistry and Chemical Engineering, Xinyang Normal University, Xinyang 464000, China \\ ${ }^{\mathrm{b}}$ Qingdao Institute of Bioenergy and Bioprocess Technology, Chinese Academy of Sciences, Qindao 266101, China
}

\section{A R T I C L E I N F O}

\section{Article history:}

Received 9 March 2011

Received in revised form 25 May 2011

Accepted 26 May 2011

Available online 2 June 2011

\section{Keywords:}

Graphene

Polyaniline

Nanocomposite

Aminophenol

Electrochemical sensor

\begin{abstract}
A B S T R A C T
An electrochemical sensor based on graphene-polyaniline (GR-PANI) nanocomposite for voltammetric determination of 4-aminophenol (4-AP) is presented. The electrochemical behavior of 4-AP at the GR-PANI composite film modified glassy carbon electrode (GCE) was investigated by cyclic voltammetry. 4-AP exhibits enhanced voltammetric response at GR-PANI modified GCE. This electrochemical sensor shows a favorable analytical performance for 4-AP detection with a detection limit of $6.5 \times 10^{-8} \mathrm{M}$ and high sensitivity of $604.2 \mu \mathrm{AmM}^{-1}$. Moreover, 4-AP and paracetamol can be detected simultaneously without interference of each other in a large dynamic range.
\end{abstract}

(C) 2011 Elsevier B.V. All rights reserved.

\section{Introduction}

Graphene-based nanomaterials have recently shown fascinating applications in electrochemical sensors and biosensors, which provide an effective sensing platform for small biomolecules [1,2]. Owing to the extraordinary electronic transport property and high electrocatalytic activity of graphene, the electrochemical reactions of analyte are greatly promoted on graphene film, resulting in enhanced voltammetric response [3,4]. Moreover, the electrochemical properties of graphene can be effectively modified by integration with other functional nanomaterials such as catalyst nanoparticles to produce versatile electrochemical sensing performance [5-9].

Polyaniline (PANI) is one of the most attractive conducting polymers, which has potential applications in electrochemical sensors and biosensors [10,11]. Owing to its good biocompatibility and inherent electroactivity, PANI can act as a suitable matrix for immobilization of biomolecules and mediator for redox and enzymatic reactions [12,13], which exhibits impressive signal amplification and antifouling properties [10]. Recent studies have demonstrated that integration of PANI with carbon nanotubes (CNTs) can significantly enhance the conductivity and electrocatalytic activity of the resultant electrode materials [14-17]. Comparing with carbon nanotubes, graphene has shown the advantages of high conductivity,

\footnotetext{
* Corresponding author. Tel.: +86 376 6391825; fax: +86 3766391825 .

E-mail address: yfanchem@gmail.com (Y. Fan).
}

ease of production and function, good biocompatibility and abundance of inexpensive source material [2]. Therefore, it is highly desirable to explore graphene-polyaniline hybrid materials for applications in electrochemical sensors and biosensors. Recently, several groups reported the graphene-polyaniline nanocomposite prepared by in situ polymerization methods [18-20]. The doping of graphene with polyaniline remarkably enhances the conductivity and mechanical strength, which exhibit excellent performance as electrode material for supercapacitors. However, to the best of our knowledge, the electrochemical sensing properties of graphene-polyaniline nanocomposite have not been investigated.

4-Aminophenol (4-AP) is the primary hydrolytic degradation product of paracetamol [21]. As a widely used antipyretic and analgesic drug, paracetamol is an effective and safe agent to relieve mild to moderate pains [22]. However, 4-AP, with significant nephrotoxicity and teratogenic effect, can be detected in pharmaceutical preparations as a degradation product of paracetamol or as a synthetic intermediate. Due to its high toxicity, the maximum content of $4-\mathrm{AP}$ in pharmaceuticals is limited to $50 \mathrm{ppm}(0.005 \%, \mathrm{w} / \mathrm{w})$ by the European [23] and United States [24] and Chinese pharmacopeias. Therefore, it is essential to develop simple, sensitive and accurate analytical methods for 4-AP detection in pharmaceutical preparations. Since 4-AP is an electroactive compound, considerable interests have been focused on the development of chemically modified electrodes for 4-AP detection [25-30].

In this work, we prepared the graphene-polyaniline (GR-PANI) nanocomposite by in situ polymerization method. The electrochemical sensor was fabricated with the GR-PANI composite film 
modified glassy carbon electrode. The electrochemical behavior and voltammetric determination of 4-AP at the GR-PANI modified electrode was investigated in detail. The results show that the GR-PANI composite film can be used as an effective electrochemical sensing interface for 4-AP.

\section{Experimental}

\subsection{Reagents and apparatus}

Graphite powder (320 mesh, spectrographic pure) was purchased from Sinopharm Chemical Reagent Co., Ltd. Aniline, ammonium peroxydisulfate (APS), hydrazine hydrate (50\%), 4aminophenol and paracetamol were purchased from Aladdin Chemistry Co., Ltd. All other chemicals were of analytical reagent grade and used as received. Water used throughout all experiments was purified with the Millipore system.

Scanning electron microscopy (SEM) images were obtained on a Hitachi S-4800 scanning electron microscope. All electrochemical experiments were performed with a $\mathrm{CHI} 850 \mathrm{C}$ electrochemical workstation ( $\mathrm{CH}$ Instruments, Shanghai, China). A conventional three-electrode system was used for all electrochemical experiments, which consisted of a platinum wire as counter electrode, an $\mathrm{Ag} / \mathrm{AgCl} / 3 \mathrm{M} \mathrm{KCl}$ as reference electrode, and a bare or modified glassy carbon electrode ( $3 \mathrm{~mm}$ diameter) as working electrode.

\subsection{Preparation of GR-PANI nanocomposite}

Graphene oxide was synthesized from graphite powder by the modified Hummers method [31,32]. Briefly, graphite was preoxidized in a mixture containing $15 \mathrm{~mL}$ concentrated $\mathrm{H}_{2} \mathrm{SO}_{4}, 5 \mathrm{~g}$ $\mathrm{K}_{2} \mathrm{~S}_{2} \mathrm{O}_{8}$ and $5 \mathrm{~g} \mathrm{P}_{2} \mathrm{O}_{5}$. The mixture was then diluted with deionized water, filtered and dried naturally. The preoxidized graphite was reoxidized by Hummers method in a mixture of concentrated $\mathrm{H}_{2} \mathrm{SO}_{4}$ and $\mathrm{KMnO}_{4}$ to produce the graphene oxide. GR-PANI nanocomposite was prepared by the literature method [18]. In a typical procedure, graphene oxide was dispersed in $1 \mathrm{M} \mathrm{HCl}$ containing $0.3 \mathrm{M}$ aniline by ultrasonication for $1 \mathrm{~h}$. Then, another solution of $0.075 \mathrm{M}$ APS in $1 \mathrm{M} \mathrm{HCl}$ was rapidly added to the mixture under vigorous stirring. The color of the mixture changed into green after about 5 minutes, indicating polymerization of aniline. After stirring at room temperature overnight, the resulting mixture was diluted by $100 \mathrm{~mL}$ of water and collected by filtration. The resulting polyaniline-graphene oxide composite was then reduced by hydrazine in water at $95^{\circ} \mathrm{C}$. Finally, the composite was dispersed in $1 \mathrm{M} \mathrm{HCl}$ containing APS, and stirred at room temperature overnight. The resulting graphene-polyaniline nanocomposite was collected by filtration and dried in vacuum. Polyaniline nanofibers were prepared by the similar procedure according to the literature report [18].

\subsection{Preparation of modified electrode}

The as-prepared GR-PANI nanocomposite was dispersed in DMF with ultrasonication for $1 \mathrm{~h}$ to get a homogenous suspension $\left(1 \mathrm{mg} \mathrm{mL}^{-1}\right)$. Then, $5 \mu \mathrm{L}$ of the suspension was dropped onto the surface of freshly polished glassy carbon electrode (GCE) and dried at room temperature, resulting in the GR-PANI modified GCE (GR-PANI/GCE). For comparison, $5 \mu \mathrm{L}$ of the homogenous suspension of graphene and PANI in DMF $\left(1 \mathrm{mg} \mathrm{mL}^{-1}\right)$ was coated on bare GCE to obtain the GR and PANI modified GCE (GR/GCE and PANI/GCE), respectively.
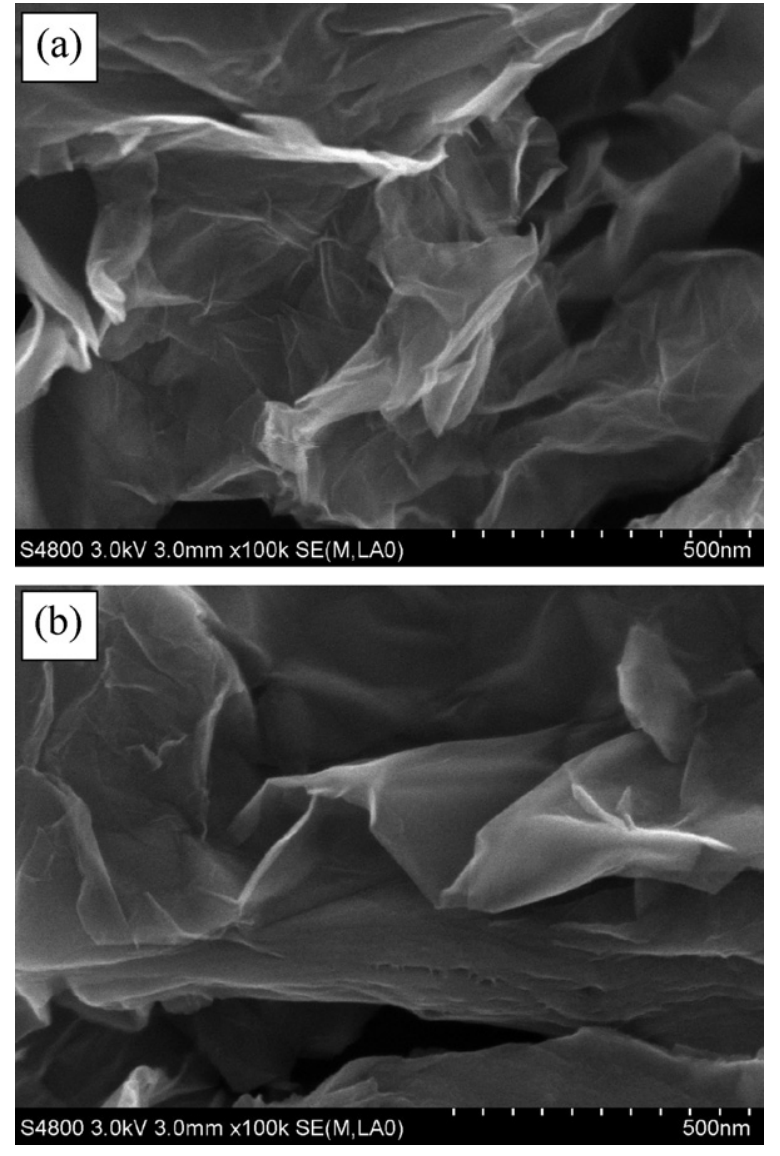

Fig. 1. SEM image of (a) GR and (b) GR-PANI nanocomposite.

\section{Results and discussion}

\subsection{Preparation and characterization of GR-PANI nanocomposite}

The GR-PANI nanocomposite was prepared by in situ polymerization according to the literature method [18]. In this method, the aniline monomer was first mixed with exfoliated graphene oxide sheets in water to form a homogenous suspension. Then, the in situ polymerization was initiated by APS to obtain the homogenous composite of graphene oxide-polyaniline. Finally, the composite was reduced to graphene by hydrazine and followed by reoxidation and reprotonation of the reduced PANI to produce the GR-PANI nanocomposite. To make graphene as the main component, the mass ratio of graphene oxide to aniline monomer in the starting materials was controlled at $4: 1$. The morphology of the as-prepared GR-PANI composite and graphene were characterized using scanning electron microscope (SEM). As shown in Fig. 1, GR-PANI exists in a layered and wrinkled form with PANI nanofibers distributed between and on the surface of graphene sheets. In the FT-IR spectra (figure not shown), the absorption peaks located at 1570 and $1135 \mathrm{~cm}^{-1}$, and $1492 \mathrm{~cm}^{-1}$ represent the quinoidal and benzenoid structure of PANI, respectively [18,20]. The CV curves of GR-PANI composites in blank phosphate buffer solution (PBS) were featureless, which was consistent with the previous report [18]. This can be ascribed to the structure change of the polyaniline nanofibers during the reduction, reoxidation and reprotonation processes in the preparation of GR-PANI. The Nyquist plots at bare GCE, GR/GCE and GR-PANI/GCE were depicted in Fig. 2. It can be seen that GR-PANI has little higher interfacial charge-transfer resistance than GR; however, both of them are very low due to the good conductivity of GR. Moreover, the neglectable Warburg region on the Nyquist plot 


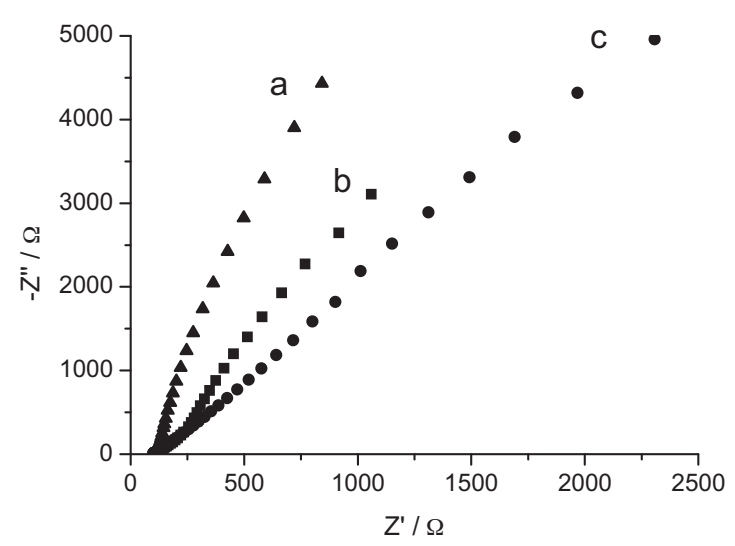

Fig. 2. Nyquist plots at (a) bare GCE, (b) GR-PANI/GCE and (c) GR/GCE in $5 \mathrm{mM}$ $\mathrm{Fe}(\mathrm{CN})_{6}{ }^{3-/ 4-}$ containing $0.1 \mathrm{M} \mathrm{KCl}$. The frequency range is from $0.01 \mathrm{~Hz}$ to $100 \mathrm{kHz}$.

of GR-PANI indicates short and equal diffusion path length of the ions in electrolyte. This can be attributed to the homogenous morphology of the GR-PANI composite, in which the ions of electrolyte only access the surface of the nanocomposite [18].

\subsection{Electrochemical behavior of 4-AP at GR-PANI/GCE}

The electrochemical behavior of 4-AP was investigated in $0.1 \mathrm{M}$ PBS ( $\mathrm{pH} 7.0$ ) by cyclic voltammetry. Fig. 3 depicts the cyclic voltammograms (CVs) of 4-AP at the bare GCE, GR/GCE, PANI/GCE and GR-PANI/GCE. At the bare GCE (Fig. 3a), 4-AP shows a quasireversible redox behavior with relative weak redox peaks at $E_{\mathrm{pa}}=0.314 \mathrm{~V}$ and $E_{\mathrm{pc}}=0.116 \mathrm{~V}$. At GR/GCE (Fig. 3b), a pair of welldefined and quasi-reversible redox peaks corresponding to the electrochemical reaction of 4 -AP were observed with $E_{\mathrm{pa}}=0.131 \mathrm{~V}$ and $E_{\mathrm{pc}}=0.081 \mathrm{~V}$. The significantly increased redox peak currents and reduced oxidation potential at the graphene film can be reasonably ascribed to its good electrocatalytic activity. In the case of PANI/GCE, the redox peak currents were further increased with $E_{\mathrm{pa}}=0.181 \mathrm{~V}$ and $E_{\mathrm{pc}}=0.057 \mathrm{~V}$. At GR-PANI/GCE, 4-AP exhibits remarkably enhanced voltammetric response comparing with GR and GR-PANI modified electrodes, with $E_{\mathrm{pa}}=0.162 \mathrm{~V}$ and $E_{\mathrm{pc}}=0.078 \mathrm{~V}$. The net values of oxidation peak current of 4-AP obtained at the GR-PANI/GCE $(48.05 \mu \mathrm{A})$ is about 1.7 and 1.4 times higher than that at the GR/GCE $(28.91 \mu \mathrm{A})$ and PANI/GCE $(34.50 \mu \mathrm{A})$, respectively. These results demonstrate that the electrochemical reactivity of $4-A P$ is remarkably promoted on the GR-PANI composite film. It is suggested that, with the synergistic

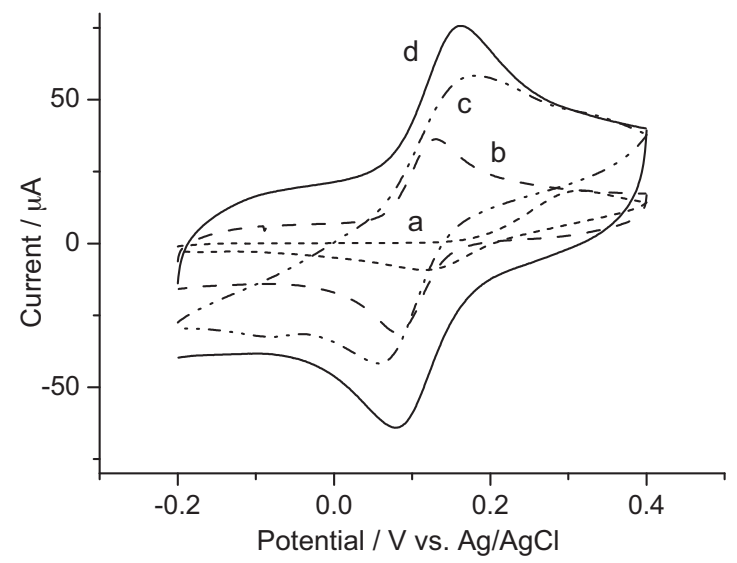

Fig. 3. CVs of $1.0 \mathrm{mM} 4-\mathrm{AP}$ at (a) bare GCE, (b) GR/GCE, (c) PANI/GCE and (d) GR-PANI/GCE in $0.1 \mathrm{M}$ PBS ( $\mathrm{pH} 7.0$ ) at scan rate of $50 \mathrm{mV} \mathrm{s}^{-1}$.

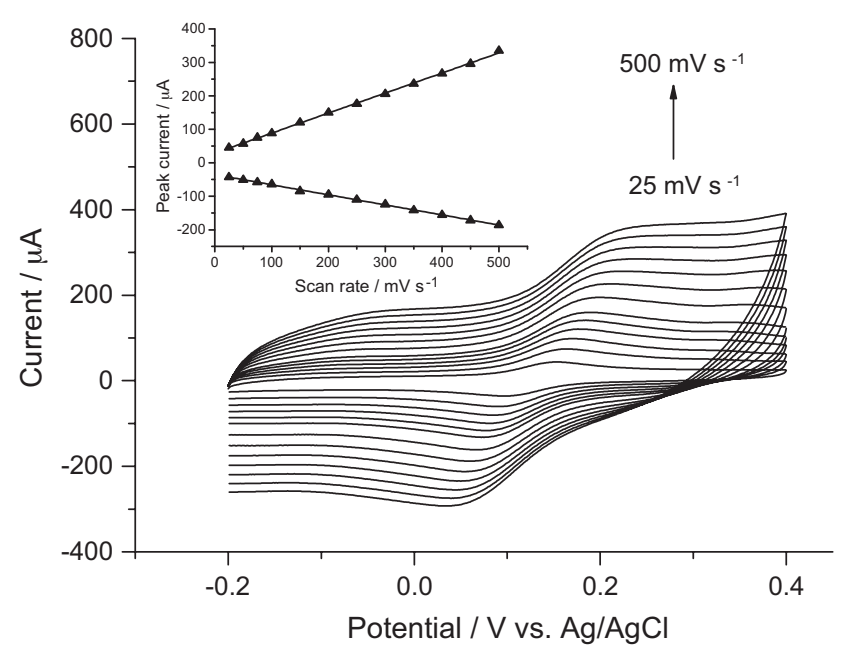

Fig. 4. CVs of $1.0 \mathrm{mM} 4-\mathrm{AP}$ at GR-PANI/GCE with different scan rates from 25 to $500 \mathrm{mV} \mathrm{s}^{-1}$ in $0.1 \mathrm{M} \mathrm{PBS}(\mathrm{pH} 7.0$ ). Insert, the plots of peak current vs. scan rate.

effects of graphene and polyaniline, the homogenous composite of GR-PANI provides an efficient microenvironment for the electrochemical reaction of 4-AP, resulting significantly enhanced voltammetric response.

\subsection{The redox mechanism of $4-A P$ at GR-PANI/GCE}

The effect of scan rate on the redox peak currents of 4-AP at the GR-PANI/GCE was investigated by cyclic voltammetry. As shown in Fig. 4, the anodic and cathodic peak currents increase with the scan rate, which are linearly proportional to scan rate in the range from 25 to $500 \mathrm{mV} \mathrm{s}^{-1}$. The linear relationship between the peak current and scan rate can be expressed by the linear regression equation as: $I_{\mathrm{pa}} / \mu \mathrm{A}=29.46+0.5909 v / \mathrm{mV} \mathrm{s}^{-1}$ $(R=0.9973)$ and $I_{\mathrm{pc}} / \mu \mathrm{A}=-35.34-0.3018 v / \mathrm{mV} \mathrm{s}^{-1} \quad(R=0.9952)$, respectively. This result indicates that the electrochemical reaction of 4-AP on the GR-PANI film is a surface-controlled process. At high scan rates ranging from 100 to $500 \mathrm{mV} \mathrm{s}^{-1}$, the linear regression equations of $E_{\mathrm{pa}}$ and $E_{\mathrm{pc}}$ vs. the logarithm of the scan rates are expressed as $E_{\mathrm{pa}}=0.3127+0.06512 \log v(R=0.9910)$ and $E_{\mathrm{pc}}=0.02670-0.04695 \log v(R=0.9951)$, respectively. According to Laviron's equation [33], the slops are equal to $2.3 R T /(1-\alpha) n F$ and $-2.3 R T / \alpha n F$ for anodic and cathodic peak, respectively. Thus, the electron transfer coefficient $(\alpha)$ and the electron transfer number $(n)$ are calculated to be 0.58 and 2, respectively. The adsorbed amount of 4-aminophenol on the surface of GR-PANI/GCE was further calculated by the following equation: $i_{\mathrm{p}}=n^{2} F^{2} A \Gamma v / 4 R T$ [33]. Based on the relationship of $i_{\mathrm{p}}$ with $v$, the value of the surface concentration of 4-aminophenol $(\Gamma)$ was obtained with the results as $2.1 \times 10^{-9} \mathrm{~mol} \mathrm{~cm}^{-2}$, indicating good adsorptivity of the GR-PANI composite film.

The effect of solution $\mathrm{pH}$ on the redox reaction of 4-AP at the GR-PANI/GCE was investigated in the range of $\mathrm{pH}$ 4.0-8.0. As shown in Fig. 5, a negative shift of both the cathodic and anodic peak potentials occurs when the $\mathrm{pH}$ value is increased. The formal potential $E^{0 \prime}$ changes linearly as a function of solution $\mathrm{pH}$ with the linear regression equation as: $E^{0 /} / \mathrm{V}=0.5110-0.05790 \mathrm{pH}(R=0.9973)$. The slope value of $-57.9 \mathrm{mV} \mathrm{pH}^{-1}$ is close to the theoretical value of $-58.6 \mathrm{mV} \mathrm{pH}^{-1}$ according to Nernst equation, suggesting equal numbers of proton and electron are involved in the redox reaction. Thus, at the GR-PANI/GCE, the redox reaction of 4-AP is a two-proton coupled two-electron process (Scheme 1) [25]. 


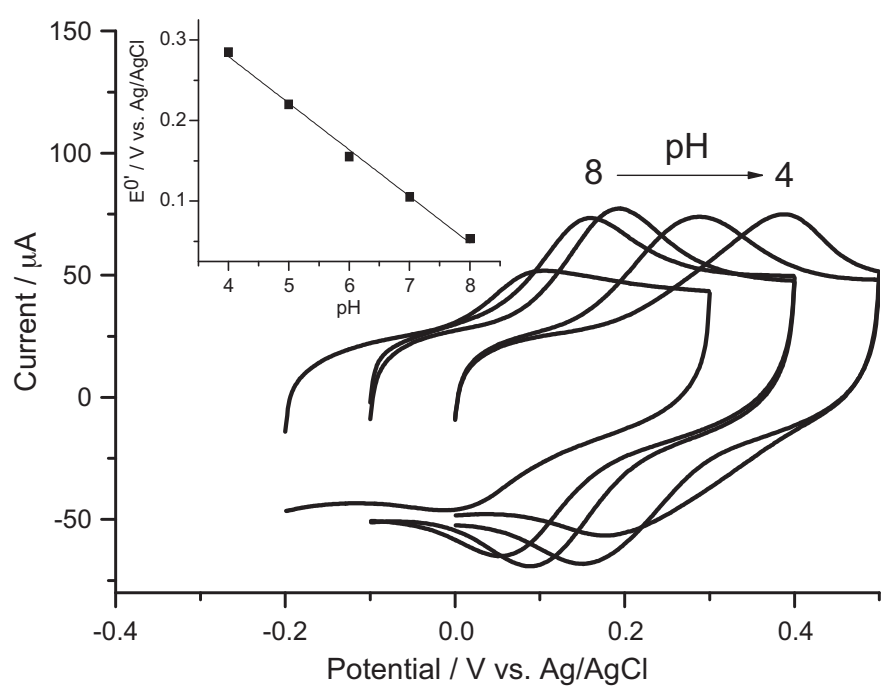

Fig. 5. CVs of $1.0 \mathrm{mM} 4-\mathrm{AP}$ at GR-PANI/GCE in $0.1 \mathrm{M}$ PBS with different $\mathrm{pH}$ values of 4.0, 5.0, 6.0, 7.0 and 8.0. Insert, the plot of formal potential vs. $\mathrm{pH}$ values. Scan rate, $50 \mathrm{mV} \mathrm{s}^{-1}$.<smiles>[14CH2]C1=CC(=O)C=CC1=N</smiles>

Scheme 1. The electrooxidation mechanism of 4-AP.

\subsection{Voltammetric determination of 4-AP}

The voltammetric determination of 4-AP was carried out in $0.1 \mathrm{M}$ PBS ( $\mathrm{pH} 7.0$ ) using differential pulse voltammetry at the GR-PANI/GCE. Fig. 6 depicts the differential pulse voltammograms (DPVs) of various concentrations of 4-AP. The peak currents increase linearly against the concentration of 4-AP within the range of $0.2-100 \mu \mathrm{M}$. The calibration curve for 4-AP shows two linear segments: the first linear segment increases from 0.2 to $20 \mu \mathrm{M}$ with the linear regression equation of $I_{\mathrm{p}} / \mu \mathrm{A}=9.822+0.1776 c / \mu \mathrm{M}$ $(R=0.9975)$, and the second linear segment increases up to $100 \mu \mathrm{M}$ with the linear regression equation of $I_{\mathrm{p}} / \mu \mathrm{A}=1.489+0.6042 \mathrm{c} / \mu \mathrm{M}$ $(R=0.9990)$. The detection limit $(\mathrm{S} / \mathrm{N}=3)$ is estimated to be $6.5 \times 10^{-8} \mathrm{M}$ and the sensitivity is 177.6 and $604.2 \mu \mathrm{AmM}^{-1}$ for two linear segment, respectively. As can be seen from Table 1, the detection limit of 4-AP at the GR-PANI/GCE is lower than those obtained on $\mathrm{p}[\mathrm{NVCzVBSA} 1] / \mathrm{CFME}\left(1 \times 10^{-6} \mathrm{M}\right)$ and carbon ionic liquid electrode $\left(1 \times 10^{-7} \mathrm{M}\right)$, and is comparable to that of graphene-chitosan modified GCE $\left(5.7 \times 10^{-8} \mathrm{M}\right)$ and SWNTs/POAPE modified GCE $\left(6 \times 10^{-8} \mathrm{M}\right)$, indicating favorable analytical performance of this electrochemical sensor.

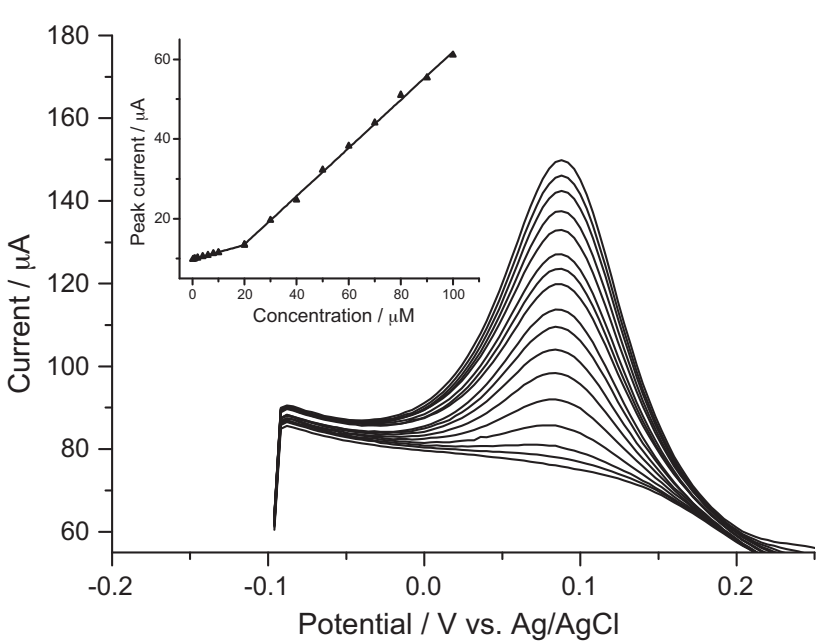

Fig. 6. DPVs of $0.2,0.6,1,2,4,6,8,10,20,30,40,50,60,70,80,90$ and $100 \mu \mathrm{M}$ of 4-AP at GR-PANI/GCE in $0.1 \mathrm{M} \mathrm{PBS}$ (pH 7.0). Insert, the plot of peak current vs. 4-AP concentration.

Since 4-AP is a degradation product of paracetamol, it necessary for an electrochemical sensor to detect 4-AP in the presence of paracetamol. Simultaneous determination of various concentrations of 4-AP and paracetamol was carried out at GR-PANI/GCE in $0.1 \mathrm{M}$ PBS ( $\mathrm{pH}$ 7.0). 4-AP and paracetamol exhibit well-defined DPV waves with peak potentials at 0.087 and $0.376 \mathrm{~V}$, respectively. The peak-to-peak separation of 4-AP and paracetamol is $0.311 \mathrm{~V}$, which is large enough for their simultaneous determination. As shown in Fig. 7, 4-AP and paracetamol can be detected simultaneously without interference of each other. The calibration curve for 4-AP also exhibits two linear segments with regression equation as: $I_{\mathrm{p}} / \mu \mathrm{A}=6.974+0.2317 c / \mu \mathrm{M}(R=0.9930)$ and $I_{\mathrm{p}} / \mu \mathrm{A}=1.233+0.5184 \mathrm{c} / \mu \mathrm{M}(R=0.9987)$ in the linear range of $1.0-20 \mu \mathrm{M}$ and $20-100 \mu \mathrm{M}$, respectively. For paracetamol, the linear detection range is $10-100 \mu \mathrm{M}$ with linear regression equation as: $I_{\mathrm{p}} / \mu \mathrm{A}=-3.762+0.3823 \mathrm{c} / \mu \mathrm{M}(R=0.9987)$. These results indicate the good selectivity of the GR-PANI based electrochemical sensing interface.

The long-term stability of the GR-PANI/GCE electrochemical sensor was investigated by examining its current response during storage in a refrigerator at $4{ }^{\circ} \mathrm{C}$. The electrochemical sensor exhibited no obvious decrease in current response in the first week and maintained about $95 \%$ of its initial value after two weeks. The relative standard deviation (RSD) of the GR-PANI/GCE electrochemical sensor in response to $50 \mu \mathrm{M} 4$-AP for ten measurements was $3.8 \%$, indicating the good reproducibility.

The interference of some small biomolecules and phenol derivatives on the determination of 4-AP was investigated. The result showed that 50-fold of glucose, uric acid, tryptophan, tyrosine, cysteine, phenol, 4-nitrophenol and 4-chlorophenol did not interfere with the DPV signal of $50 \mu \mathrm{M} 4$-AP (peak current change $< \pm 5 \%$ ).

Table 1

Comparison of the performances of some 4-AP electrochemical sensors.

\begin{tabular}{|c|c|c|c|c|}
\hline Electrode & LOD (M) & Linear range $(\mu \mathrm{M})$ & Sensitivity $\left(\mu \mathrm{A} \mathrm{mM}^{-1}\right)$ & Reference \\
\hline Graphene-chitosan/GCE & $5.7 \times 10^{-8}$ & $0.2-550$ & 33 & [25] \\
\hline CILE $^{\mathrm{a}}$ & $1.0 \times 10^{-7}$ & $0.3-1000$ & - & [26] \\
\hline p[NVCzVBSA1]/CFME ${ }^{\mathrm{b}}$ & $1 \times 10^{-6}$ & - & - & [27] \\
\hline SWNTs/POAPE/GCE & $6 \times 10^{-8}$ & $0.2-100$ & 1800 & [28] \\
\hline GR-PANI/GCE & $6.5 \times 10^{-8}$ & $0.2-2020-100$ & $177.6 ; 604.2$ & This work \\
\hline
\end{tabular}

a Carbon ionic liquid electrode.

b Poly[N-vinylcarbazole-co-vinylbenzene sulfonic acid]/carbon fibre microelectrode.

c Single-wall carbon nanotubes/poly(4-aminopyridine). 


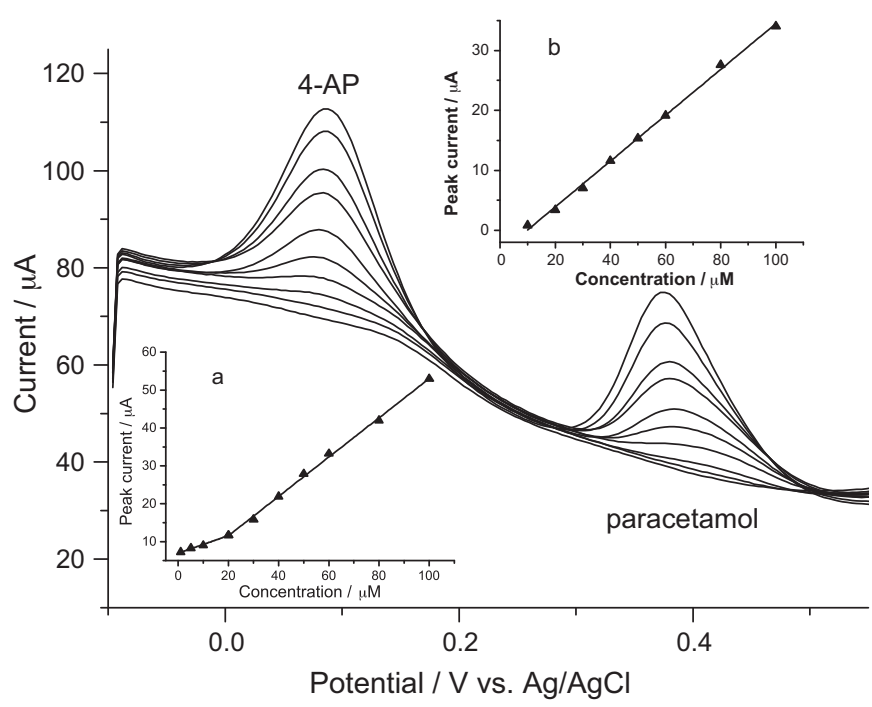

Fig. 7. DPVs of $1,5,10,20,30,40,50,60,80$ and $100 \mu \mathrm{M}$ of 4 -AP and paracetamol at GR-PANI/GCE in $0.1 \mathrm{M}$ PBS (pH 7.0). Insert, (a) the plot of peak current vs. 4-AP concentration, (b) the plot of peak current vs. paracetamol concentration.

\section{Conclusions}

In summary, GR-PANI nanocomposite was prepared and utilized as electrochemical sensing interface for 4-AP. The electrochemical behavior of 4-AP at the GR-PANI composite film modified electrode was studied. The results indicate that the GR-PANI nanocomposite can provide a favorable microenvironment for the electrochemical reaction of 4-AP, resulting in enhanced the voltammetric response. This GR-PANI based electrochemical sensor processes low detection limit, high sensitivity and long-term stability for the determination of 4-AP. Moreover, 4-AP and paracetamol can be detected simultaneously without interference of each other in a large dynamic range. The GR-PANI nanocomposite may offer a new approach for developing graphene-based electrochemical sensors and biosensors.

\section{Acknowledgements}

This work was financially supported by the National Natural Science Foundation of China (No. 21002082) and the Key Project of Chinese Ministry of Education (No. 210129), and the Specific Funding for the Technology centers of Henan Province (No. 102102313101).

\section{References}

[1] Y. Shao, J. Wang, H. Wu, J. Liu, I.A. Aksay, Y. Lin, Graphene based electrochemical sensors and biosensors: a review, Electroanalysis 22 (2010) 1027-1036.

[2] M. Pumera, A. Ambrosi, A. Bonanni, E.L.K. Chng, H.L. Poh, Graphene for electrochemical sensing and biosensing, Trends Anal. Chem. 29 (2010) 954-965.

[3] M. Zhou, Y. Zhai, S. Dong, Electrochemical sensing and biosensing platform based on chemically reduced graphene oxide, Anal. Chem. 81 (2009) 5063-5613.

[4] L. Tang, Y. Wang, Y. Li, H. Feng, J. Lu, J. Li, Preparation, structure, and electrochemical properties of reduced graphene sheet films, Adv. Funct. Mater. 19 (2009) 2782-2789.

[5] L. Li, Z. Du, S. Liu, Q. Hao, Y. Wang, Q. Li, T. Wang, A novel nonenzymatic hydrogen peroxide sensor based on $\mathrm{MnO}_{2}$ /graphene oxide nanocomposite, Talanta 82 (2010) 1637-1641.

[6] C. Shan, H. Yang, D. Han, Q. Zhang, A. Ivaska, L. Niu, Graphene/AuNPs/chitosan nanocomposites film for glucose biosensing, Biosens. Bioelectron. 25 (2010) 1070-1074.

[7] E. Jin, X. Lu, L. Cui, D. Chao, C. Wang, Fabrication of graphene/prussian blue composite nanosheets and their electrocatalytic reduction of $\mathrm{H}_{2} \mathrm{O}_{2}$, Electrochim. Acta 55 (2010) 7230-7234.
[8] H. Yin, Y. Zhou, Q. Ma, S. Ai, Q. Chen, L. Zhu, Electrocatalytic oxidation behavior of guanosine at graphene, chitosan and $\mathrm{Fe}_{3} \mathrm{O}_{4}$ nanoparticles modified glassy carbon electrode and its determination, Talanta 82 (2010) 1193-1199.

[9] Y Fan, H.T. Lu, J.H. Liu, C.P. Yang, Q.S. Jing, Y.X. Zhang, X.K. Yang, K.J. Huang Hydrothermal preparation and electrochemical sensing properties of $\mathrm{TiO}_{2}$ graphene nanocomposite, Colloids Surf., B 83 (2011) 78-82.

[10] C. Dhand, M. Das, M. Datta, B.D. Malhotra, Recent advances in polyaniline based biosensors, Biosens. Bioelectron. 26 (2011) 2811-2821.

[11] D.W. Hatchett, M. Josowicz, Composites of intrinsically conducting polymers as sensing nanomaterials, Chem. Rev. 108 (2008) 746-769.

[12] Z. Wang, S. Liu, P. Wu, C. Cai, Detection of glucose based on direct electron transfer reaction of glucose oxidase immobilized on highly ordered polyaniline nanotubes, Anal. Chem. 81 (2009) 1638-1645.

[13] H. Chang, Y. Yuan, N. Shi, Y. Guan, Electrochemical DNA biosensor based on conducting polyaniline nanotube array, Anal. Chem. 79 (2007) 5111-5115.

[14] E. Granot, B. Basnar, Z. Cheglakov, E. Katz, I. Willner, Enhanced bioelectrocatalysis using single-walled carbon nanotubes (SWCNTs)/polyaniline hybrid systems in thin-film and microrod structures associated with electrodes, Electroanalysis 18 (2006) 26-34.

[15] T. Yang, N. Zhou, Y. Zhang, W. Zhang, K. Jiao, G. Li, Synergistically improved sensitivity for the detection of specific DNA sequences using polyaniline nanofibers and multi-walled carbon nanotubes composites, Biosens. Bioelectron. 24 (2009) 2165-2170.

[16] Y. Li, Y. Umasankar, S.M. Chen, Polyaniline and poly(flavin adenine dinucleotide) doped multi-walled carbon nanotubes for $p$-acetamidophenol sensor, Talanta 79 (2009) 486-492.

[17] M. Li, L. Jing, Electrochemical behavior of acetaminophen and its detection on the PANI-MWCNTs composite modified electrode, Electrochim. Acta 52 (2007) 3250-3257.

[18] K. Zhang, L.L. Zhang, X.S. Zhao, J. Wu, Graphene/polyaniline nanofiber composites as supercapacitor electrodes, Chem. Mater. 22 (2010) 1392-1401.

[19] D.W. Wang, F. Li, J.Zhao, W. Ren, Z.G. Chen, J. Tan, Z.S. Wu, I. Gentle, G.Q. Lu, H.M. Cheng, Fabrication of graphene/polyaniline composite paper via in situ anodic electropolymerization for high-performance flexible electrode, ACS Nano 3 (2009) 1745-1752.

[20] X. Yan, J. Chen, J. Yang, Q. Xue, P. Miele, Fabrication of free-standing, electrochemically active, and biocompatible graphene oxide-polyaniline and graphene-polyaniline hybrid papers, ACS Appl. Mater. Interfaces 2 (2010) 2521-2529.

[21] A. Yesilada, H. Erdogan, M. Ertan, Second derivative spectrophotometric determination of $p$-aminophenol in the presence of paracetamol, Anal. Lett. 24 (1991) 129-138.

[22] R.M.D. Carvalho, R.S. Freire, S. Rath, L.T. Kubota, Effects of EDTA on signal stability during electrochemical detection of acetaminophen, J. Pharm. Biomed. Anal. 34 (2004) 871-878.

[23] The European Pharmacopeial Convention, The sixth edition European Pharmacopoeia, The European Pharmacopeial Convention, 2007, p. 49.

[24] The United States Pharmacopeial Convention, The United States Pharmacopoeia 27-NF (The National Formulary), 2004, p. 2494

[25] H. Yin, Q. Ma, Y. Zhou, S. Ai, L. Zhu, Electrochemical behavior and voltammetric determination of 4-aminophenol based on graphene-chitosan composite film modified glassy carbon electrode, Electrochim. Acta 55 (2010) 7102-7108.

[26] A. Safavi, N. Maleki, O. Moradlou, A selective and sensitive method for simultaneous determination of traces of paracetamol and $p$-aminophenol in pharmaceuticals using carbon ionic liquid electrode, Electroanalysis 20 (2008) 2158-2162.

[27] M. Jamal, S.A. Sarac, E. Magner, Conductive copolymer-modified carbon fibre microelectrodes: electrode characterization and electrochemical detection of p-aminophenol, Sens. Actuators B 97 (2004) 59-66.

[28] Z. Wang, H. Zhu, H. Zhang, G. Gao, Z. Sun, H. Liu, X. Zhao, Fabrication of the singlewall carbon nanotube compound polymer film electrode and the simultaneous electrochemical behavior of aminophenol isomers, Electrochim. Acta 54 (2009) 7531-7535.

[29] N.G. Karousos, S.M. Reddy, Determination of 4-aminophenol using the quartz crystal microbalance sensor, Analyst 127 (2002) 368-372.

[30] P.J. Lamas-Ardisana, P. Queipo, P. Fanjul-Bolado, A. Costa-García, Multiwalled carbon nanotube modified screen-printed electrodes for the detection of $p$ aminophenol: optimisation and application in alkaline phosphatase-based assays, Anal. Chim. Acta 615 (2008) 30-38.

[31] N.I. Kovtyukhova, P.J. Ollivier, B.R. Martin, T.E. Mallouk, S.A. Chizhik, E.V. Buzaneva, A.D. Gorchinskiy, Layer-by-layer assembly of ultrathin composite films from micron-sized graphite oxide sheets and polycations, Chem. Mater. 11 (1999) 771-778.

[32] W.S. Hummers, R.E. Offeman, Preparation of graphitic oxide, J. Am. Chem. Soc. 80 (1958) 1339.

[33] E. Laviron, General expression of the linear potential sweep voltammogram in the case of diffusionless electrochemical systems, J. Electroanal. Chem. 101 (1979) 19-28.

\section{Biographies}

Yang Fan received his $\mathrm{PhD}$ in physical chemistry from Fujian Institute of Research on the Structure of Matter, Chinese Academy of Sciences. He then spent 2008-2009 as 
a postdoctoral research associate at Purdue University. He is currently an associate professor at Xinyang Normal University. His research focuses on nanomaterials and molecular materials for electrochemical applications.

Jin-Hang Liu is currently a graduate student at Xinyang Normal University. His thesis project is concerned with the development of graphene-based materials for electrochemical applications.
Chun-Peng Yang received her MSc in chemistry from Fuzhou University. She is currently a research assistant at Qingdao Institute of Bioenergy and Bioprocess Technology, Chinese Academy of Sciences.

Meng Yu is currently an undergraduate student at Xinyang Normal University.

Peng Liu is a professor at Xinyang Normal University. His research focuses on inorganic mineral materials. 